\title{
Influence of Tempering Temperature on Low Cycle Fatigue of High Strength Steel
}

\author{
Hyuksun KWON, ${ }^{1) *}$ Frédéric BARLAT, ${ }^{1)}$ Myounggyu LEE, ${ }^{1)}$ Younil $\mathrm{CHUNG}^{21}$ and Sangho $\mathrm{UHM}^{2)}$ \\ 1) Graduate Institute of Ferrous Technology (GIFT), Pohang University of Science and Technology (POSTECH), $77 \mathrm{Cheongam-}$ \\ ro, Nam-gu, Pohang, Gyeongbuk 790-784, Republic of Korea. \\ 2) POSCO Global R\&D Center, Songdo-dong, Yeonsu-gu, Incheon, 406-840 Korea (South).
}

(Received on October 6, 2013; accepted on November 27, 2013)

\begin{abstract}
In this study, the mechanical and low cycle fatigue properties for a heat-treatment steel subjected to quenching and tempering (QT) were evaluated. The steel had a modified chemical composition with respect to a conventional material and was subjected to tempering at various temperatures. It was shown that the material tempered at $250^{\circ} \mathrm{C}$ exhibited superior fatigue properties in the short life regions. Carbon atom clusters in concentration of 18 at\% in martensite were observed using atom probe tomography (APT) for the steel tempered at $250^{\circ} \mathrm{C}$. It is believed that these clusters contribute to the improvement of fatigue properties by hindering the motion of dislocations.
\end{abstract}

KEY WORDS: advanced high strength steel; heat treatment; low cycle fatigue; tempering process.

\section{Introduction}

In the automotive industry, there has been a continuous trend toward the weight reduction of vehicles in response to the need for cost savings, fuel efficiency and reduction in $\mathrm{CO}_{2}$ emissions. Considerable efforts have been made to reduce the thickness of components without a significant loss in their stiffness and fatigue properties. For this purpose, advanced high strength steels (AHSS) have been increasingly used for automotive chassis components. Quenching and tempering (QT) heat treatment is a technique used to produce high strength steel with a martensite microstructure by heating the steel over a temperature of $900^{\circ} \mathrm{C}$. After the heating process, the component is formed and cooled rapidly. Due to high strength and low elongation, the components produced through the QT method tend to exhibit inferior fatigue properties. However, a proper tempering treatment can effectively improve the fatigue properties of AHSS by securing a higher elongation with a relatively negligible or tolerable loss of strength.

Extensive studies have been carried out to improve the fatigue strength of various steel grades through effective tempering processes. ${ }^{1)}$ For instance, in low-alloy steels, the threshold stress intensity factor for crack propagation was higher after tempering at $370^{\circ} \mathrm{C}$ for $2 \mathrm{~h} .^{2)}$ The literature also describes the relationship between microstructure, fracture resistance and fatigue performance. In hot-forged steels, the volume fractions of different phases formed due to austempering were shown to have an important effect on the fracture toughness. ${ }^{3)}$ In different studies, ${ }^{4,5)}$ the effects of retained austenite morphology on low and high cycle test

* Corresponding author: E-mail: kwonhs@posco.com DOI: http://dx.doi.org/10.2355/isijinternational.54.979 results in austempered ductile irons were reported. Other aspects of the microstructure were also investigated. In particular, among the different microstructures obtained through heat-treatment processes like QT, air cooling and step cooling, the highest fatigue strengths were achieved in those with ferrite-bainite microstructure. ${ }^{6)}$ Finally, additional alloying elements such as $\mathrm{B}$ and $\mathrm{Cr}-\mathrm{Mo}$ were used to investigate the influence of boron on the austenite grain size and fatigue performance. ${ }^{7}$

The most important factors in the QT process are the tempering temperature and time. A low tempering temperature and a short tempering time have a little influence on fatigue resistance due to their insignificant effect on material strength and elongation. In contrast, an excessive tempering temperature and time decrease the strength of the steel, and thereby, yield lower fatigue resistance. For instance, the fatigue performances of $55 \mathrm{NiCrMoV} 7$ steel were reduced for elevated tempering temperature over $500^{\circ} \mathrm{C}$ because of the drop of hardness accompanied with cyclic softening. ${ }^{8)}$ Thus, to achieve the desired fatigue properties in high strength steels, it is crucial to understand the tempering and subsequent deformation mechanisms in order to find the conditions leading to optimal performances.

In this study, a heat treatment steel, which is widely used as sheet material in automotive chassis components, was investigated. Its chemical composition was slightly modified compared to that of a standard registered alloy. This modified steel was subjected to conventional processing followed by tempering at different temperatures. The low cycle fatigue properties corresponding to these different conditions were measured. The fatigue performances were investigated and tentatively explained based on the different microstructures observed. 


\section{Experimental Procedure}

The chemical compositions of the steel used in this study and that of the conventional steel are listed in Table 1. In view of alloy design principles, the $\mathrm{Mn}$ content was increased to lower the austenitization temperature, promote fine grain and enhance hardenability. $\mathrm{N}$ and Ti were added to improve the bake hardening response and achieve high yield strength. The heat treatment process consisted of quenching and tempering. First, the steel was heated up to $950^{\circ} \mathrm{C}$ with a heating rate of $3.2^{\circ} \mathrm{C} / \mathrm{s}$, holding for 5 minutes and quenched using water. Tempering treatments at different temperatures between 100 and $340^{\circ} \mathrm{C}$ were performed for 30 minutes with a heating rate of $3.2^{\circ} \mathrm{C} / \mathrm{s}$ and followed by air cooling. Specimens machined out of the conventional steel were tempered in a standard way at $340^{\circ} \mathrm{C}$ for comparison purpose. In order to find the optimized conditions, specimens of the modified steel were tempered at 100, 200, 250, 300,340 and $400^{\circ} \mathrm{C}$ for the tensile specimens and at 100 , 250 , and $340^{\circ} \mathrm{C}$ for the fatigue test specimens.

The tensile tests were performed at room temperature using a 60 tons ZWICK testing machine. The specimen gage length was $50 \mathrm{~mm}$ and the tests were done according to the JIS Z 2241 standards. Hardness tests were conducted using the Vickers method. The low cycle fatigue tests were performed at room temperature according to the ISO 12106 standard. The main fatigue test range was between $10^{3}$ and $10^{5}$ cycles. The applied frequency was $0.2 \mathrm{~Hz}$ and the strain amplitude ranged between \pm 0.1 and $\pm 0.7 \%$. The alignment setting for anti-buckling in tension compression loading was within class 2 . The selected failure criterion was a $25 \%$ load drop. In order to assess the durability performance of a real chassis component, fatigue tests for a torsion beam axle were conducted on a MTS Flextest200 tester.

Optical metallographic studies were performed on speci-

Table 1. Chemical composition of heat treatment steels.

\begin{tabular}{ccccccc}
\hline Material & $\begin{array}{c}\mathrm{C} \\
\text { (wt.\%) }\end{array}$ & $\begin{array}{c}\mathrm{Si} \\
(\text { wt.\%) }\end{array}$ & $\begin{array}{c}\mathrm{Mn} \\
(\text { wt.\%) }\end{array}$ & $\begin{array}{c}\mathrm{P} \\
(\text { wt.\%) }\end{array}$ & $\begin{array}{c}\mathrm{S} \\
(\text { wt.\%) }\end{array}$ & Others \\
\hline $\begin{array}{c}\text { Conventional } \\
\text { steel }\end{array}$ & $<0.25$ & $<0.42$ & $<0.82$ & $<0.03$ & $<0.015$ & $\mathrm{Al}, \mathrm{Ni}, \mathrm{B}$ \\
$\begin{array}{c}\text { Modified } \\
\text { steel }\end{array}$ & $<0.33$ & $<0.51$ & $<1.51$ & $<0.02$ & $<0.007$ & $\begin{array}{c}\mathrm{Al}, \mathrm{Ti}, \mathrm{W}, \\
\mathrm{B}, \mathrm{N}\end{array}$ \\
\hline
\end{tabular}

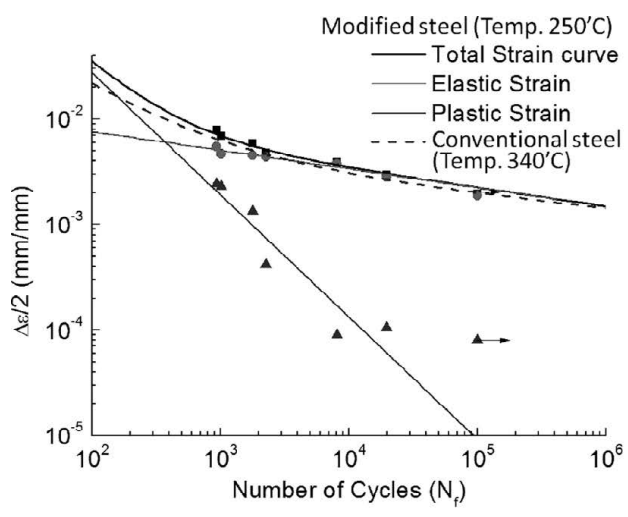

(a) mens etched with a $2 \%$ nital solution. Transmission electron microscopy (TEM) observations were conducted to characterize the dislocation structure evolution after fatigue for different tempering temperatures. 3D atom probe tomography (APT), which allows the investigation of the nano-structure morphology, was performed at the Pohang National Nano Technology Center to extract tomography images of carbon and other elements.

\section{Test Results}

\subsection{Tensile and Low Cycle Fatigue Test}

Figure 1 shows the variations of the tensile strength and total elongation as a function of the tempering temperature. In the tempering range of 100 to $250^{\circ} \mathrm{C}$, the drop in the tensile strength was significant, but the increase in elongation was comparatively small. In the range of 250 to $340^{\circ} \mathrm{C}$, the elongation increased significantly while the tensile strength kept decreasing. At temperatures higher than $340^{\circ} \mathrm{C}$ the increment in elongation was not substantial relative to the decrease in tensile strength. In steels, it is usually considered that high elongation is more beneficial in the region of short fatigue life, while high tensile strength has more benefits in the long life region. ${ }^{10)}$ Therefore, a good compromise between strength and elongation is needed and the curves of Fig. 1 suggest that optimum conditions might occur for temperatures ranging between 250 and $350^{\circ} \mathrm{C}$.

The fatigue life curves ( $\varepsilon / \mathrm{N}$ curves) in Fig. 2 represent the

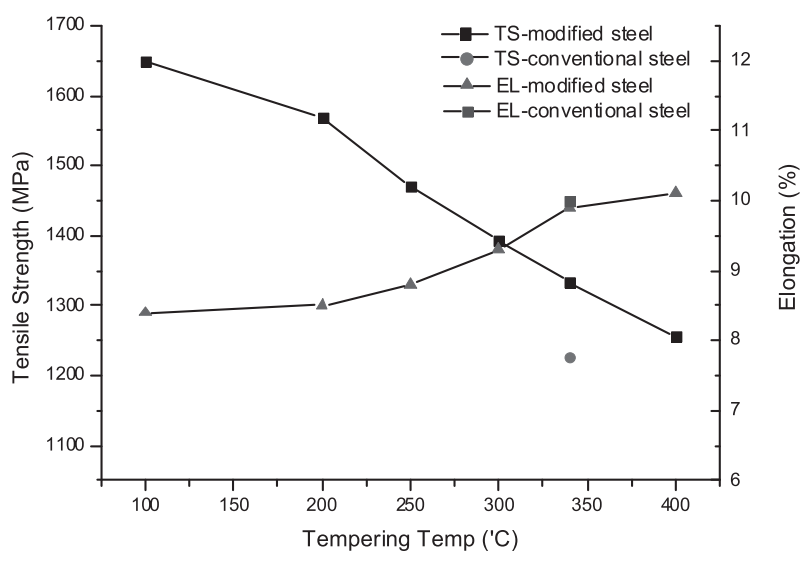

Fig. 1. Variation in tensile properties with tempering temperature.

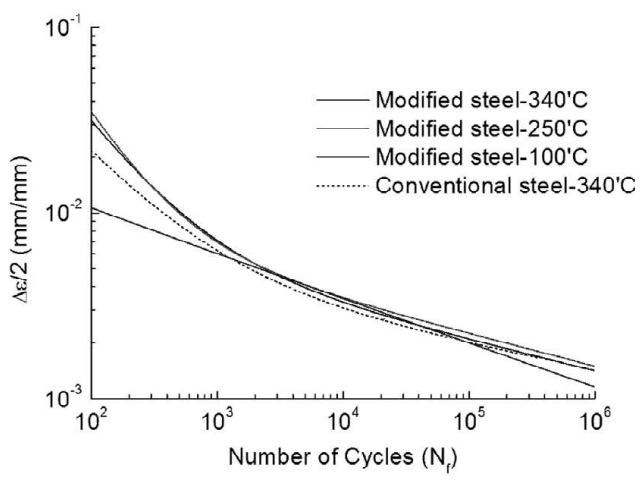

(b)

Fig. 2. Low cycle fatigue life curves of modified steel tempered at $250^{\circ} \mathrm{C}$ (a) and obtained at various tempering temperatures (b). 
relationship between the total strain amplitude and the fatigue life, namely, the number of cycles at fracture. The fatigue life curve is usually well captured by the Coffin-Manson Eq. (1)

$$
\varepsilon_{\text {total }}=\frac{\sigma_{\mathrm{f}}^{\prime}}{E}\left(2 N_{f}\right)^{\mathrm{b}}+\varepsilon_{\mathrm{f}}^{\prime}\left(2 N_{f}\right)^{\mathrm{c}}
$$

where $2 N_{f}$ represents the reversal to failure, $\sigma_{\mathrm{f}}^{\prime}$ is the fatigue strength coefficient and $\mathrm{b}$ is the strength exponent. $\varepsilon_{\mathrm{f}}^{\prime}$ is the fatigue ductility coefficient and $\mathrm{c}$ is the ductility exponent. For the $\varepsilon / \mathrm{N}$ curves of the modified steel treated at $250^{\circ} \mathrm{C}$, the strain was decomposed into its elastic and plastic components as shown in Fig. 2(a). The fatigue life curves obtained for the specimens tempered at various temperatures are shown in Fig. 2(b). Note that the scale of the vertical axis is different from that of Fig. 2(a). These results show that the modified steel tempered at $250^{\circ} \mathrm{C}$ exhibits fatigue properties superior to those of the modified steels tempered at $100^{\circ} \mathrm{C}$ and $340^{\circ} \mathrm{C}$, and of the reference conventional material. Alternatively, in order to assess the performance of each material, the fatigue lives for strain amplitudes of $0.6 \%$ and $0.2 \%$ are compared in Table 2 . The fatigue lives

Table 2. Fatigue life of heat treatment steels.

\begin{tabular}{lrrc}
\hline $\begin{array}{c}\text { Material/Tempering } \\
\text { temp }\end{array}$ & $\begin{array}{r}\text { Fatigue life at } \\
\Delta \varepsilon / 2= \pm 0.6 \%\end{array}$ & $\begin{array}{c}\text { Fatigue life at } \\
\Delta \varepsilon / 2= \pm 0.2 \%\end{array}$ & $\begin{array}{c}\text { Fatigue life ratio } \\
\text { (Modified/Conven. } \\
\text { steel cycles) }\end{array}$ \\
\hline Conventional steel $/ 340^{\circ} \mathrm{C}$ & 11844 cycles & 105783 cycles & - \\
Modified steel $/ 340^{\circ} \mathrm{C}$ & 10047 cycles & 132179 cycles & $0.85 / 1.25$ \\
Modified steel $/ 250^{\circ} \mathrm{C}$ & 19757 cycles & 195702 cycles & $1.67 / 1.85$ \\
Modified steel $/ 100^{\circ} \mathrm{C}$ & 9381 cycles & 99684 cycles & $0.79 / 0.94$ \\
\hline
\end{tabular}

of the modified steels tempered at $240^{\circ} \mathrm{C}$ were respectively 1.67 and 1.85 times larger than those of the conventional steel.

The maximum stress achieved in a low cycle fatigue tests for the modified steel tempered at different temperatures is shown in Fig. 3. Although imperceptible for the steel tempered at $100^{\circ} \mathrm{C}$, cyclic softening was observed for all the materials. However, this cyclic softening was more significant for higher tempering temperature.

\subsection{Microstructure Observations}

Lath tempered martensite with no distinct difference in optical microstructure was observed at all tempering temperatures, e.g., $100^{\circ} \mathrm{C}$ (a), $250^{\circ} \mathrm{C}$ (b), and $340^{\circ} \mathrm{C}$ (c), as shown in Fig. 4. Transmission electron microscopy (TEM) images of the modified steel are shown in Figs. 5(a), 5(b)

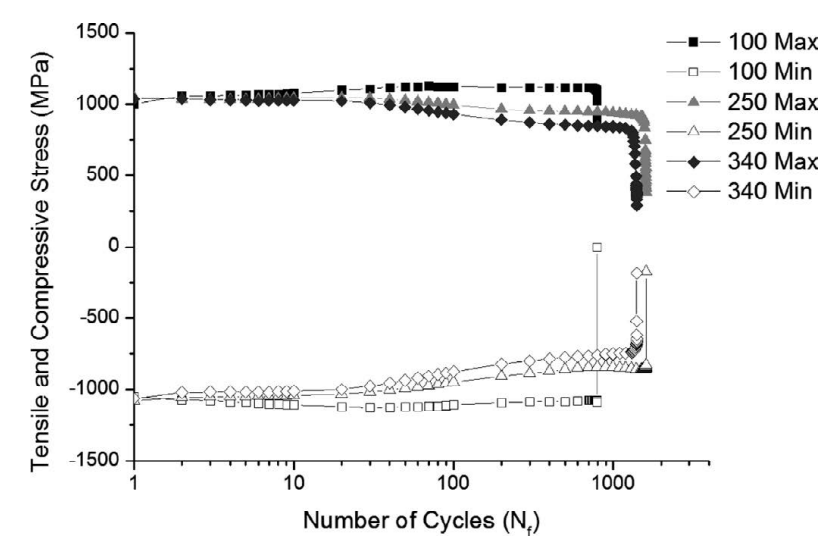

Fig. 3. Variation of maximum stresses as a function of the number of cycles.

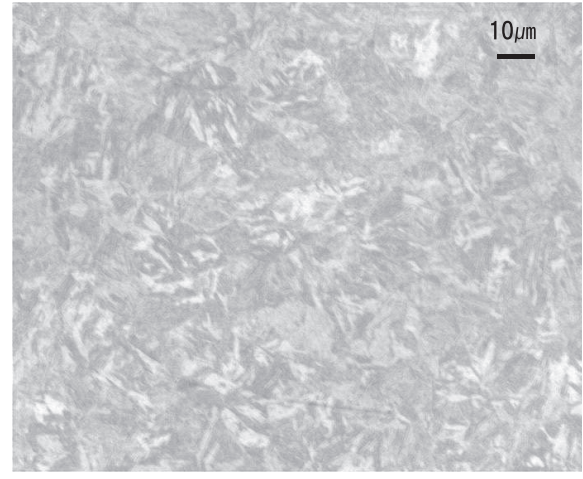

(a)

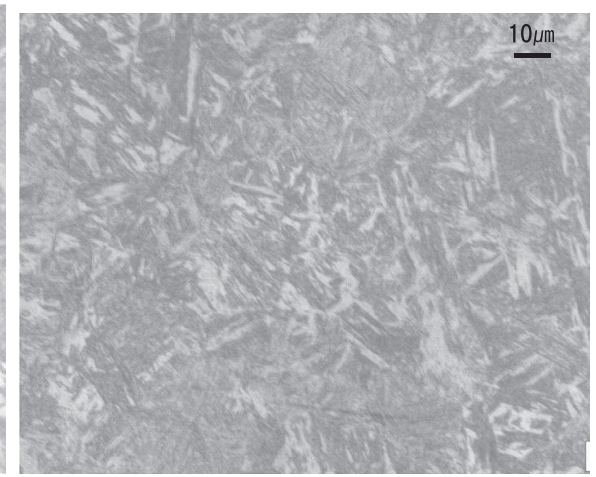

(b)

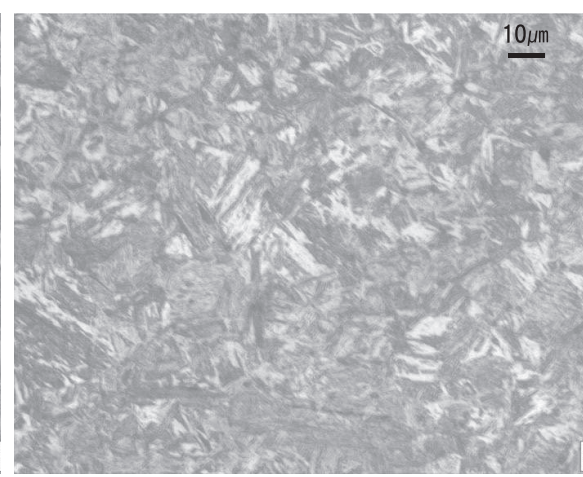

(c)

Fig. 4. Optical microstructures tempered at $100^{\circ} \mathrm{C}(\mathrm{a}), 250^{\circ} \mathrm{C}(\mathrm{b})$ and $340^{\circ} \mathrm{C}$ (c).

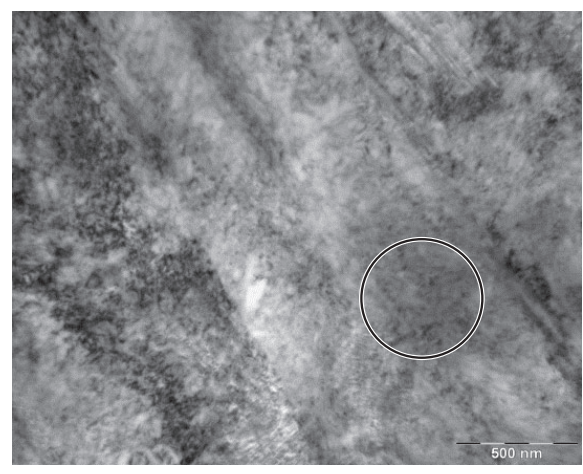

(a)

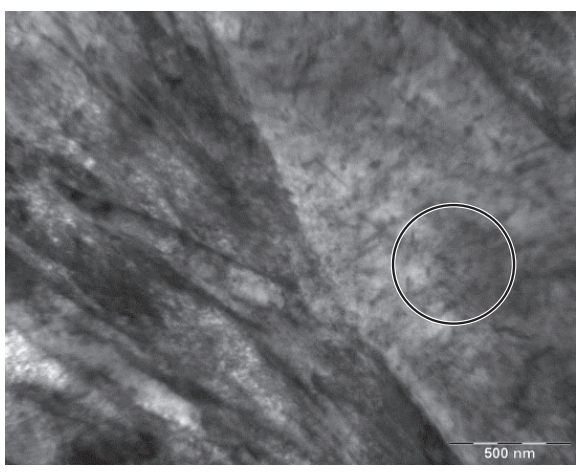

(b)

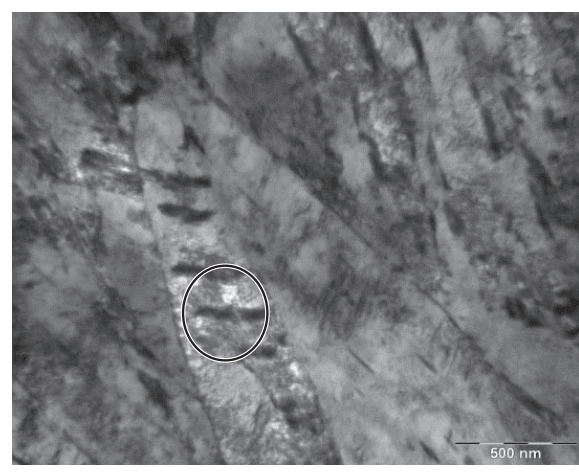

(c)

Fig. 5. TEM observations at $100^{\circ} \mathrm{C}(\mathrm{a}), 250^{\circ} \mathrm{C} \mathrm{(b)}$ and $340^{\circ} \mathrm{C}(\mathrm{c})$. 
and 5(c) for these respective tempering conditions. Finely dispersed carbides were discovered for tempering at $100^{\circ} \mathrm{C}$ while medium sized carbides were observed for tempering at $250^{\circ} \mathrm{C}$. For the steel tempered at $340^{\circ} \mathrm{C}$, coarse carbides were observed between lath boundaries within martensite packets but they were not easily identifiable.

Figure 6 shows the TEM images of these steels after 1000 fatigue cycles at a $0.7 \%$ strain amplitude. Planar slip was recognized for the specimen tempered at $100^{\circ} \mathrm{C}$, Fig. 6(a). However, dislocation pile-ups were observed in ferrite for the specimen tempered at $250^{\circ} \mathrm{C}$, Fig. $6(\mathrm{~b})$, and in the lath boundaries for the specimen tempered at $340^{\circ} \mathrm{C}$, Fig. 6(c). This is an important observation because it was shown that a rearrangement of the dislocation structure is believed to produce dislocation pile-ups and crack nucleation, which usually occurs at grain boundaries. ${ }^{11,12)}$ In particular, this may be promoted by the presence of precipitates and other small foreign particles, which oppose the formation of saturation dislocation structures. ${ }^{11,12)}$

Generally, a tempered steel with medium carbon content exhibits complex martensitic microstructures that depends on tempering temperature. It is usually reported that, at low temperature, rearrangement of the carbon atoms takes place. However, when the tempering temperature increases, various carbide precipitates are formed. ${ }^{13,14)}$ Thus, in the present study, carbon atoms were mapped using 3D atom probe tomography (APT) on needle like specimens after tempering at 100,250 and $340^{\circ} \mathrm{C}$, as shown in Figs. 7(a), 7(b) and 7(c), respectively. In the APT selected area, the measured carbon concentration, respectively equal to $0.223,0.151$ and $0.098 \mathrm{wt} \%$, was observed to decrease as tempering temperature increased. This indicates that carbides are likely to form in the presently studied steel when the temperature increases.

\subsection{Material Applications}

A suspension system, which is designed to reduce the car vibration and noise, undergoes repeated loads in service and is subjected to fatigue damage. Therefore, as an application of the present work, the coupled torsion beam axle, which is used in car suspension components, were manufactured using the modified steel processed through quenching and tempering. In order to verify the performance of the chassis component, durability tests were performed. Figure 8(a)

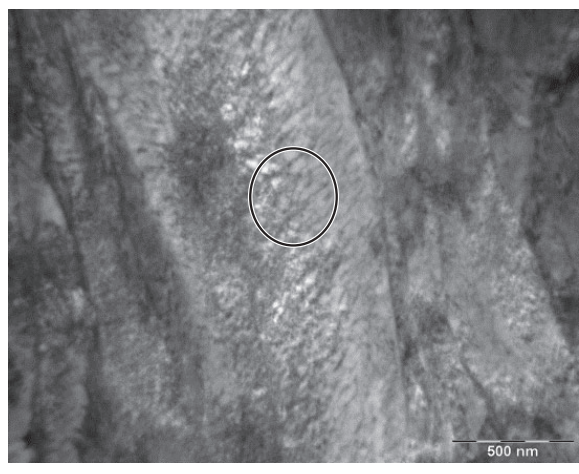

(a)

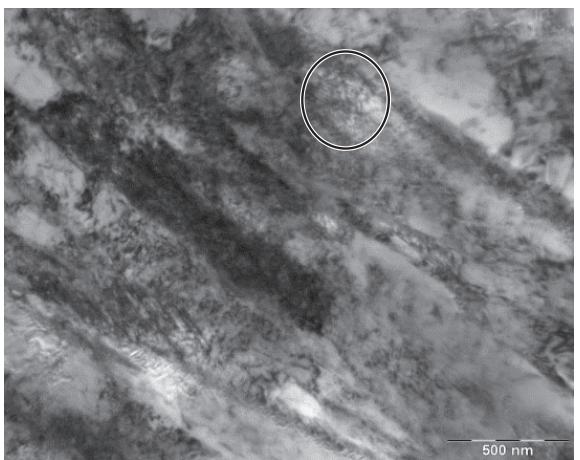

(b)

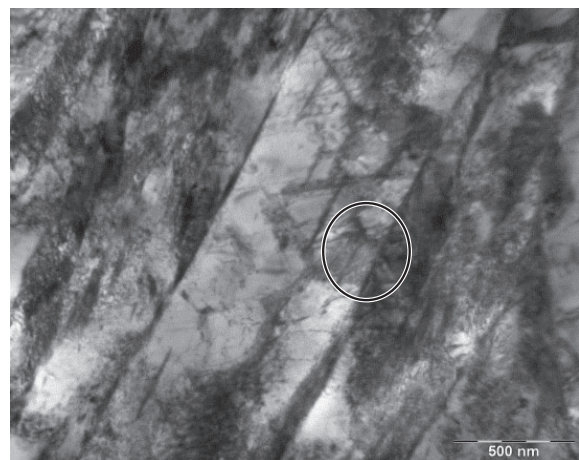

(c)

Fig. 6. TEM observations after fatigue test at $100^{\circ} \mathrm{C}(\mathrm{a}), 250^{\circ} \mathrm{C} \mathrm{(b)}$ and $340^{\circ} \mathrm{C}(\mathrm{c})$.

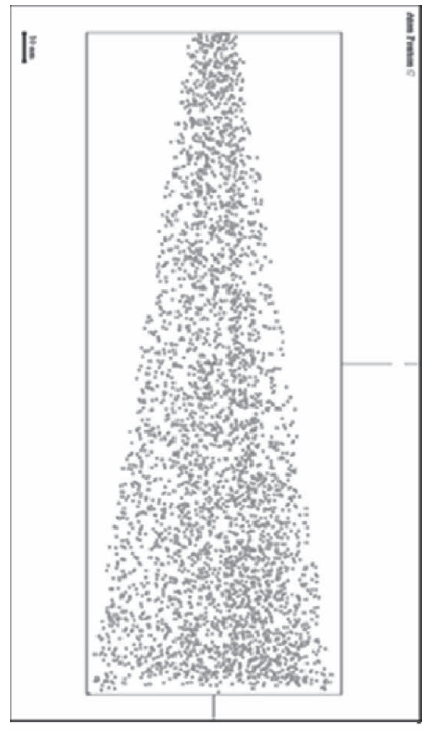

$89 n m \cdot 89 n m \cdot 248 n m$

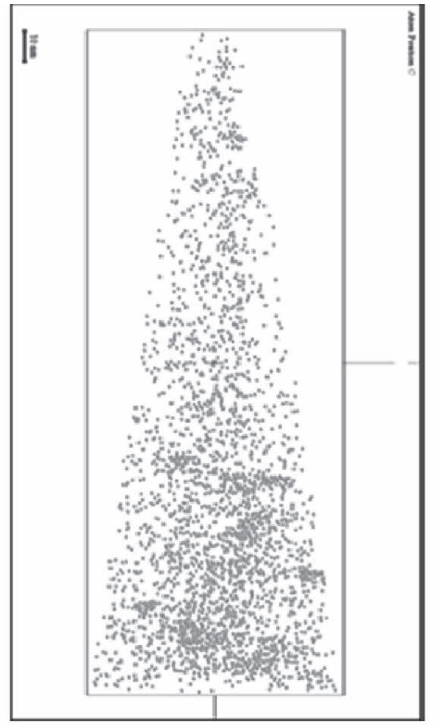

$82 \mathrm{~nm} \cdot 82 \mathrm{~nm} \cdot 225 \mathrm{~nm}$

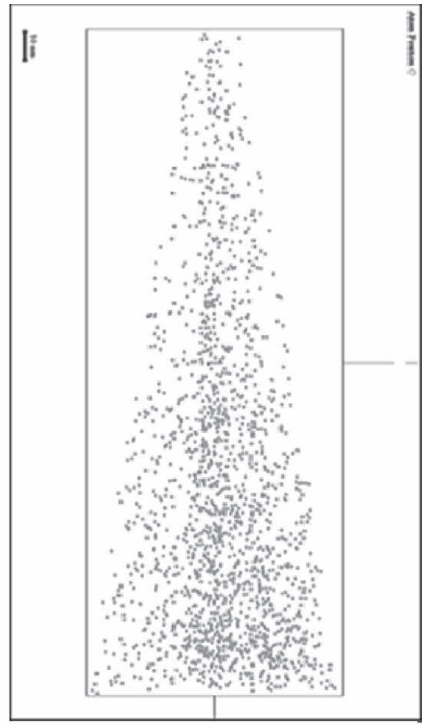

$88 \mathrm{~nm} \cdot 88 \mathrm{~nm} \cdot 243 \mathrm{~nm}$

(b)

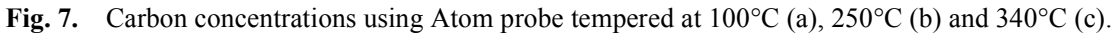




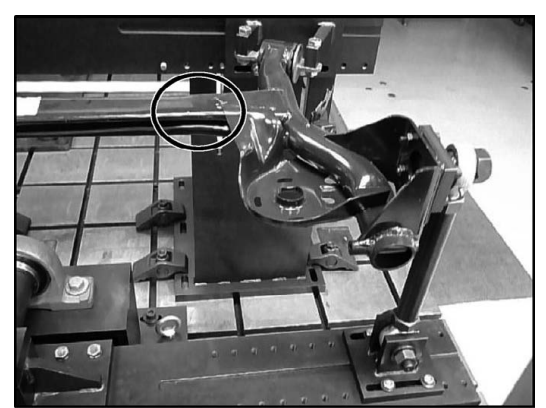

(a)

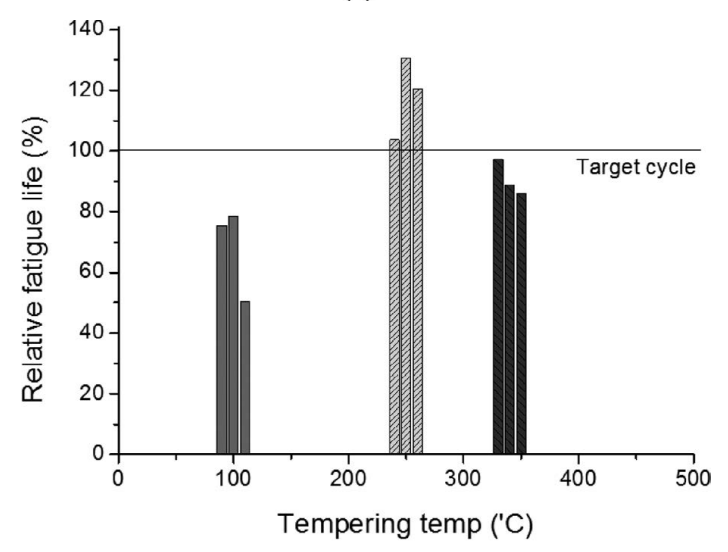

(b)

Fig. 8. Durability test of coupled torsion beam axle(a) and relative fatigue life refering tempering temperature (b).

shows the experimental set-up of the durability test where the circle represents the critical area in which crack initiates. This area was correctly predicted from an analysis using the low cycle fatigue curves previously evaluated. ${ }^{15)}$ In addition, relative fatigue cycle refer to tempering temperature is shown in Fig. 8(b), it was found that the modified steel tempered at $250^{\circ} \mathrm{C}$ satisfied the design target life.

\section{Discussion}

In terms of fatigue properties, the different steels can be ranked from best to worst in the following order: modified steel tempered at $250^{\circ} \mathrm{C}$, modified steel tempered at $340^{\circ} \mathrm{C}$, conventional steel and modified steel tempered at $100^{\circ} \mathrm{C}$. Prior studies indicated that the presence of grain boundary cementite reduces the cohesive strength of the interfaces and softens the material matrix. ${ }^{16)}$ Specimen tempered at $100^{\circ} \mathrm{C}$ exhibited the lowest fatigue performance. As shown in Fig. 1 , this tempering has not significant effect on the mechanical properties and, as observed from Fig. 6, it does not lead to any significant amount of particles in the microstructure. Therefore, this lowest performance seems to be due to the fully martensitic microstructure, which tends to behave as a brittle material. ${ }^{9)}$ The modified steel tempered at $250^{\circ} \mathrm{C}$ demonstrated superior fatigue performance compared to the other steels although it did not exhibit the highest ductility. Finally, for the steel tempered at the higher temperature of $340^{\circ} \mathrm{C}$, the low cycle fatigue performance deteriorated presumably due to crack nucleation resulting from excessive cementite coarsening or large extent of precipitation as observed in the microstructure.

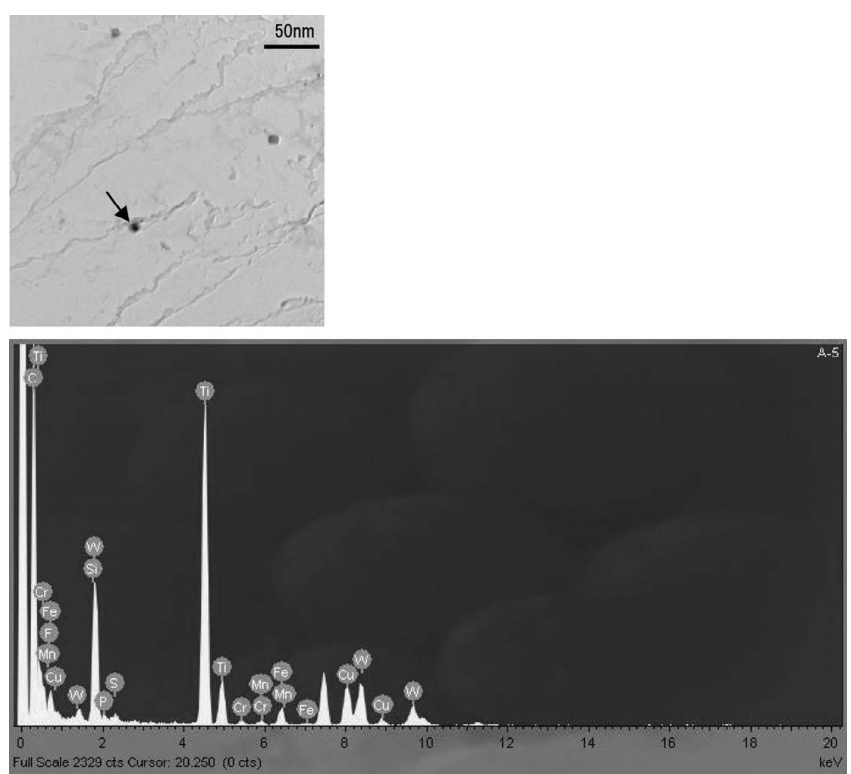

Fig. 9. Back scatter images (a) and EDS analysis (b) of modified steel tempered at $250^{\circ} \mathrm{C}$.

In order to elucidate this behavior, the microstructure of the modified steel tempered at $250^{\circ} \mathrm{C}$ was investigated in more detail. Energy dispersive X-ray spectroscopy (EDS) images of this steel are shown in Fig. 9. The diffraction pattern indicates the presence of carbide particles containing $\mathrm{W}$ and Ti. These carbide particles might act as retardation to dislocation pile-ups in lath boundaries, which have a beneficial effect on fatigue properties. However, it is unlikely that random dispersed carbides can oppose the complex dislocation motion in a low cycle fatigue test. ${ }^{12)}$

An alternate explanation for this performance is based on the distribution of carbon in the material. In the present study, using APT experiments, nano-volume with size of about $50 \mathrm{~nm}$ with carbon atom concentration as high as 18 at $\%$, were detected as shown in Fig. 10. Similar measurements of high carbon concentration using APT and their correlation with material strengthening were recently reported. ${ }^{17-19)}$ In a tempered bainitic steel, high carbon atom concentrations were discriminated from different sources, namely, carbon cluster, cementite and $\varepsilon$-carbide. ${ }^{17)}$ Moreover, a relationship between strength and carbon atoms segregated to lath boundary in the various carbon steels in the as-quenched condition was clearly established. ${ }^{18)}$ In heavily drawn pearlitic steel wires ${ }^{19)}$ a homogeneous carbon atom distribution changed to carbon-enriched areas at the prior lamellar boundary due to an increase of the tempering temperature. In this study, Fig. 10 shows another 3D APT mapping of a number of elements, namely, Fe, Mn, Si and C which demonstrates that carbon is distributed in clusters, not in precipitates. Based on all the above results, the carbon atom concentration of 18 at $\%$ observed in Fig. 10 is believed to be carbon clusters that resist dislocation motion effectively during low cycle fatigue test because of the associated stress field that these clusters are inducing.

The optimization of the overall low cycle fatigue properties in the high and low strain amplitude range using temperature control inevitably requires a judicious balance between strength and ductility. The present study indicates 
$53 \mathrm{~nm} \times 53 \mathrm{~nm} \times 137 \mathrm{~nm}$
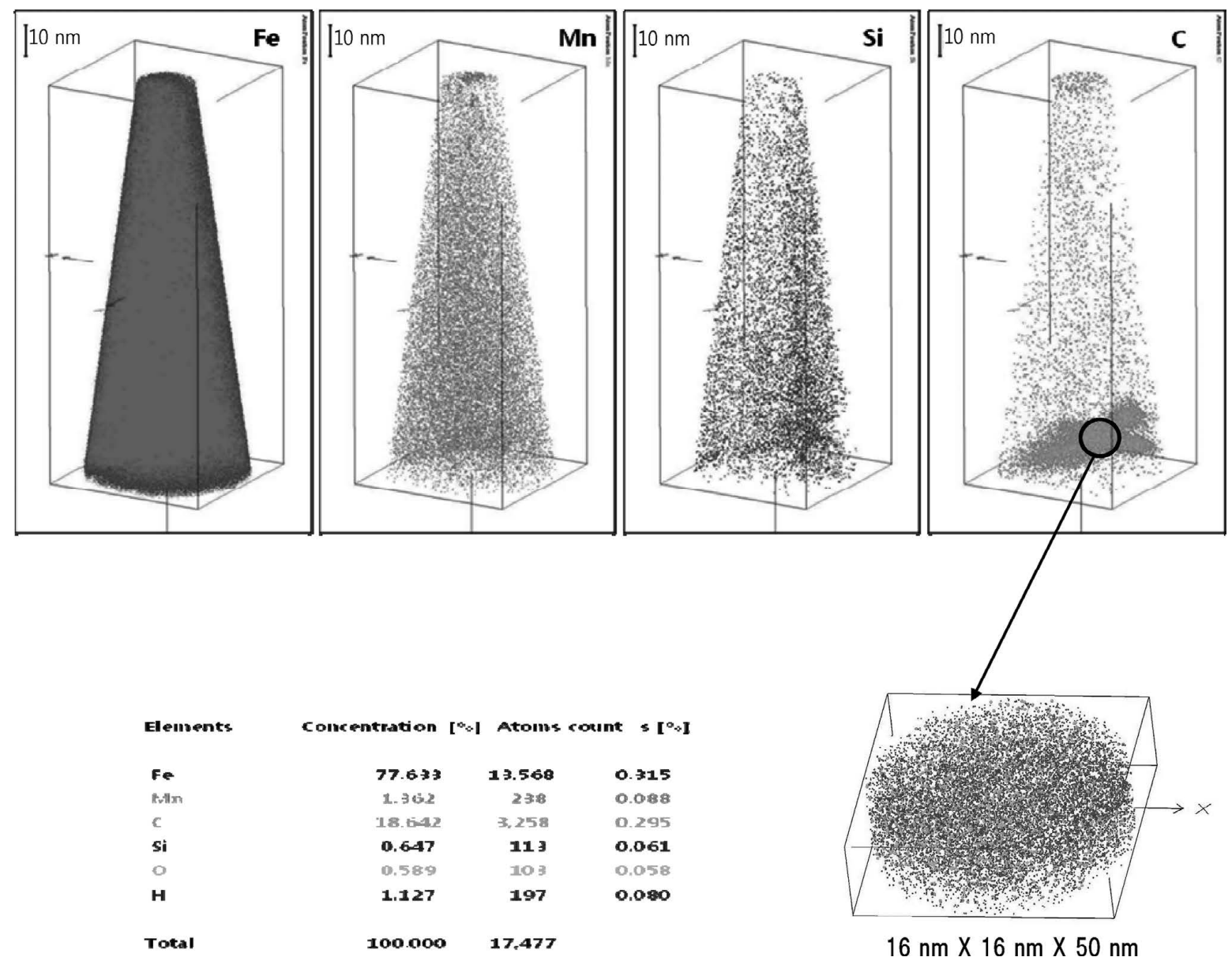

Fig. 10. Atom probe of modified steel tempered at $250^{\circ} \mathrm{C}$.

that a modified steel exhibited higher fatigue properties in the short life region when it was tempered at $250^{\circ} \mathrm{C}$. The good fatigue performance of this modified steel was tentatively explained in a qualitative manner based on the presence of carbon clusters in the microstructure. However, this analysis does not provide a basis for approaching complex and basic probabilistic fatigue problems.

\section{Conclusions}

In this study, the mechanical and low cycle fatigue properties of heat treatment steel processed through quenching have been accurately evaluated with respect to variations in the tempering temperature. When this temperature increased, the tensile strength decreased and the total elongation increased. A modified steel tempered at $250^{\circ} \mathrm{C}$ provided better fatigue results than that tempered at $100^{\circ} \mathrm{C}$, both of which outperformed the conventional and modified steel tempered at $340^{\circ} \mathrm{C}$. This is believed to be mainly due to carbon clustering formation in the lath martensite microstructure.

\section{REFERENCES}

1) G. E. Totten: Steel Heat Treatment Handbook, Marcel Dekker, New York, (1997), 73.

2) D. Y. Wei: Int. J. Fatigue, 26 (2004), 437.

3) P. Farsetti and A. Blarasin: Int. J. Fatigue, 10 (1988), No. 3, 153.

4) C. K. Lin, P. K. Lai and T. S. Shih: Int. J. Fatigue, 18 (1995), No. $5,297$.

5) C. K. Lin and T. P. Hung: Int. J. Fatigue, 18 (1995), No. 5, 309.

6) S. Sankaran: Mater. Sci. Eng., A345 (2003), 328.

7) H. Suzuki: Microstr. Mech. Behav., Mater., 1-986 (1985), 671.

8) Z. Zhang: Int. J. Fatigue, 29 (2007), 336.

9) B. C. De Cooman: Materials Design, GRIPS media GmbH, Bad Harzburg, (2007), 296.

10) J. A. Bannantine: Fundamentals of Metal Fatigue Analysis, PrenticeHall, New Jersey, (1990), 61.

11) M. Klesnil: Fatigue of Metallic Materials, Elsevier, New York, (1980), 47.

12) S. Suresh: Fatigue of Materials, Cambridge University Press, Cambridge, (1991), 67.

13) W-s. Lee: J. Mater. Proc. Tech., 87 (1999), 198.

14) G. Krauss: Mater. Sci. Eng., A273-275 (1999), 40.

15) H. S. Kwon: Int. Automotive Body Cong., GAMC, Berlin, (2011).

16) C. S. Lee: Mater. Sci. Eng., A241 (1998), 30.

17) F. G. Caballero: ASM Int., 42A (2011), 3660.

18) B. Hutchinson: Acta Mater., 59 (2011), 5845.

19) J. Takahashi: Acta Mater., 60 (2012), 387. 